\title{
Liquid methanol Monte Carlo simulations with a refined potential which includes polarizability, nonadditivity, and intramolecular relaxation
}

\author{
Maximiliano Valdéz-González, a Humberto Saint-Martin, and \\ Jorge Hernández-Cobos \\ Instituto de Ciencias F \\ 62251 Cuernavaca, Morelos, Mexico \\ Regla Ayala and Enrique Sanchez-Marcos

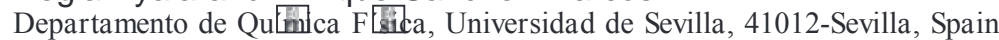 \\ Ivan Ortega-Blake $\mathrm{b}$ \\ Departamento de F \\ 97310, Yucatán, Mexico
}

Received 9 March 2007; accepted 2 October 2007; published online 12 December 2007国

\begin{abstract}
Monte Carlo simulations of liquid methanol were performed using a refined ab initio derived potential which includes polarizability, nonadditivity, and intramolecular relaxation. The results present good agreement between the energetic and structural properties predicted by the model and those predicted by ab initio calculations of methanol clusters and experimental values of gas and condensed phases. The molecular level picture of methanol shows the existence of both rings and linear polymers in the methanol liquid phase. (C) 2007 American Institute of Physics.
\end{abstract}

DOI: $10.1063 / 1.2801538$ [5:

\section{INTRODUCTION}

Nowadays it is possible to use refined potentials in numerical simulations of physicochemical systems involving small molecules ${ }^{1-3}$ and attain sufficiently good agreement with the experimental observations. The reliability that such validation confers upon the simulations allows for the construction of a molecular image that contributes to a better understanding of the phenomena. It seems that construction of refined potentials requires paying attention to molecular properties such as polarizability, intramolecular relaxation, and nonadditivity. ${ }^{4-7}$ These flexible potentials can be adjusted to ab initio data of the molecule and the intermolecular interaction, with no reference to a particular thermodynamic state of the condensed phase, allowing for its unbiased use in any condition. A great effort has been made for the development of water potentials ${ }^{1,4,8-10}$ and in some cases for other small molecules. ${ }^{11,12}$ It is indeed convenient to extend the use of this tool to other systems and also to determine to what extent the inclusion of different molecular properties that add dearly to the computational cost is required for the proper reproduction of the experimental data. ${ }^{13}$

Liquid methanol is of great interest given its many uses, particularly that as a common organic solvent and more recently as an important fuel alternative. ${ }^{14}$ Additionally, a lot of work has been devoted to the understanding of its unusual physical properties ${ }^{15}$ that have been associated with a peculiar molecular behavior that is conducive to methanol being

\footnotetext{
Electronic mail: maxvalde@fis.unam.mx

b丣 leave from Instituto de Ciencias Físicas, Universidad Nacional $\mathrm{Au}-$ tónoma de México.
}

certainly one of the most structured liquids. In the crystal phase methanol presents long one-dimensional chains of hydrogen bonds. ${ }^{16,17}$ It has therefore been thought that something similar could be occurring in the liquid phase and be responsible for its peculiar behavior. Several numerical simulations $^{18-23}$ and neutron diffraction experiments ${ }^{24-26}$ have produced data that support this view. On the other hand, experimental results of neutron diffraction, ${ }^{27,28} \mathrm{x}$-ray scattering, ${ }^{29,30}$ and $x$-ray emission spectroscopy ${ }^{31}$ have been taken to support the existence of cyclic clusters of methanol in the liquid phase. Kashtanov et al. ${ }^{31}$ have suggested that numerical simulations could be using potentials that are not able to reproduce the hydrogen bonding network in ring structures. There is a substantial number of numerical simulations of methanol ${ }^{18-23,32-34}$ and some of them which include polarizability ${ }^{35-38}$ have shown the need for refined potentials.

In this work a refined methanol-methanol potential that uses the mobile charge densities in harmonic oscillators MCDHO mhodel $^{4}$ which includes polarizability, nonadditivity, and intramolecular relaxation is presented. The potential is adjusted to ab initio surfaces and tested in the reproduction of $\mathrm{ab}$ initio methanol clusters, their energies, and structures. The potential is then used in Monte Carlo simulations of liquid methanol. This serves to test the potential and determine the validity of its use. In addition we tested how accounting for different molecular properties, such as polarizability and intramolecular relaxation, affects the reproduction of the experimental properties. The quality of the potential helps us to further the understanding of the behavior of liquid methanol. 
TABLE I. Structural parameters for the minimum energy methanol monomer predicted at the MP2 and QCC

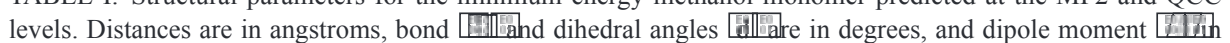
Debye.

\begin{tabular}{|c|c|c|c|c|c|}
\hline Method & $\mathrm{r} \mathrm{CO}$ & r鸟 & 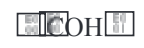 & $\mathrm{d}$ 用COH & $\square$ \\
\hline MP2/cc-pvDZ & 1.4171 & 0.9656 & 106.3 & 179.88 & 1.63 \\
\hline $\mathrm{MP} 2 / 6-31++\mathrm{G}^{* *}$ & 1.4290 & 0.9644 & 108.5 & 179.88 & 1.99 \\
\hline $\mathrm{MP} 2 / 6-311++\mathrm{G}^{* *}$ & 1.4217 & 0.9544 & 107.3 & 179.88 & 1.93 \\
\hline MP2/aug-cc-pVDZ & 1.4342 & 0.9659 & 107.9 & 180.00 & 1.71 \\
\hline MP2/cc-pvTZ & 1.4188 & 0.9594 & 107.4 & 179.83 & 1.65 \\
\hline MP2/aug-cc-pvTZ & 1.4239 & 0.9611 & 108.0 & 179.81 & 1.70 \\
\hline MP2/cc-pVQZ & 1.4177 & 0.9577 & 108.0 & 179.83 & 1.68 \\
\hline MP2/aug-cc-pVQZ & 1.4353 & 0.9658 & 107.9 & 179.6 & 1.70 \\
\hline QCC TZV $2 p, 2 \mathrm{~d} W+^{\mathrm{a}}$ & 1.4286 & 0.9583 & 107.6 & 180.0 & 1.81 \\
\hline
\end{tabular}

${ }^{\mathrm{a}}$ Reference 34.

\section{METHODS}

\section{A. Potential energy surfaces}

The methanol-methanol potential was developed by reproducing ab initio energy surfaces for the intramolecular relaxation, the dipole moments of different methanol structures, the pairwise interaction, and the nonadditive terms of the intermolecular interaction. Molecular orbital calculations for all cases were done with the GAUSSIAN98 program. ${ }^{39} \mathrm{We}$ considered in the calibration procedure Gaussian basis sets $6-31++\mathrm{G}^{* *}$ and $6-311++\mathrm{G}^{* *}$ and correlation-consistent basis sets cc-pVDZ, aug-cc-pVDZ, cc-pVTZ, and cc-pVQZ. ${ }^{40-42}$

Of course a compromise has to be made between the computational cost and the quality of the molecular calculation due to the fact that a great number of structures need to be considered. Hence, in order to determine the optimal level of calculation we looked into the prediction of various properties reported at different levels of molecular theory. Table I shows the optimal structures for the monomer of methanol predicted with different basis set sizes at the MP2 and QCC levels. It is clear that there is a fast convergence of the structural parameters and that the aug-cc-pVDZ basis set yields a good approximation to more expensive and complete basis sets. In a previous study Wang et al. compared the vibrational spectra of methanol predicted with different basis sets. ${ }^{43}$ It was found that a basis set of similar size yielded a reasonable approximation to the experimental spectra. The dipole moment shows more discrepancy, with a value $10 \%$ larger for the most extended basis set. However, since the value predicted by the aug-cc-pVDZ basis set is closer to the experimental dipole moment ${ }^{44}$ of $1.69 \mathrm{D}$, we decided to use this basis set for the description of the intramolecular surface.

Table II shows the structural parameters of the optimal methanol dimer predicted by different basis sets. It is clear that there is convergence in the predicted dimer configuration. The corresponding energies are also presented and compared to other data in the literature. The values corresponding to the three largest basis sets were computed with structures optimized with a $6-31++\mathrm{G}^{* *}$ basis set and monomers kept frozen in the dimer optimization. ${ }^{45}$ Even if they are not fully comparable they provide a good reference point on the expected convergence value, and since they correspond to a partial optimization it is clearly a lower limit. The optimal dimers for the six smaller basis sets were optimized in their own basis set and counterpoise copborrection ap-

TABLE II. Structural parameters of the optimal methanol dimer predicted at the MP2 level ieft columns

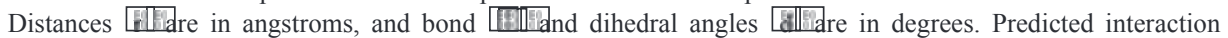

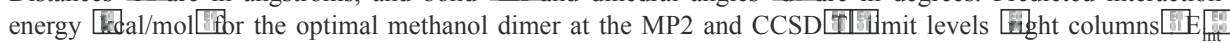
corresponds to the energy of the dimer minus the energy of the relaxed monomers, $\mathrm{E}_{\mathrm{def}}$ is the deformation energy, and $\mathrm{E}_{\mathrm{int}}=\mathrm{E}$ m $\mathrm{H} \mathrm{E}_{\mathrm{def}}$ is the interaction energy. The relative time for a single point calculation for each basis set is also presented.

\begin{tabular}{|c|c|c|c|c|c|c|c|c|c|c|}
\hline Basis set & $\begin{array}{c}\mathrm{r} \\
\mathrm{O} \cdot \mathrm{H}\end{array}$ & $\begin{array}{c}\mathrm{r} \\
\mathrm{O} \cdot \mathrm{O}\end{array}$ & $\begin{array}{c}\mathrm{DH} \cdot \mathrm{O} \\
\mathrm{OH}\end{array}$ & HO $\cdot \mathrm{H}$ & $\frac{\mathrm{d}}{\mathrm{COH} \cdot \mathrm{O}}$ & $\begin{array}{c}\mathrm{d} \\
\mathrm{OH} \cdot \mathrm{OC}\end{array}$ & $\mathrm{E}$ & $\mathrm{E}_{\mathrm{def}}$ & $\mathrm{E}_{\text {int }}$ & $\begin{array}{l}\text { Rel. } \\
\text { time }\end{array}$ \\
\hline cc-pVDZ & 1.887 & 2.819 & 159.3 & 101.7 & 109.1 & -20.7 & -3.53 & 0.20 & -3.33 & 1.0 \\
\hline $6-31++\mathrm{G}^{* *}$ & 1.887 & 2.853 & 172.5 & 117.9 & 109.0 & 16.9 & -5.22 & 0.11 & -5.11 & 1.5 \\
\hline $6-311++\mathrm{G}^{* *}$ & 1.886 & 2.846 & 171.9 & 122.5 & 98.3 & 30.0 & -4.97 & 0.11 & -4.86 & 5.9 \\
\hline aug-cc-pVDZ & 1.887 & 2.847 & 168.2 & 112.7 & 132.3 & -6.7 & -5.22 & 0.11 & -5.11 & 15.7 \\
\hline cc-pVTZ & 1.872 & 2.802 & 160.4 & 131.0 & 97.8 & 24.9 & -5.09 & 0.19 & -4.90 & 39.0 \\
\hline aug-cc-pVTZ & 1.877 & 2.836 & 169.4 & 117.0 & 129.9 & 1.0 & -5.60 & 0.11 & -5.49 & 3486.3 \\
\hline cc-pVQZ & & & & & & & & & $-5.21^{\mathrm{a}}$ & - \\
\hline cc-pV5Z & & & & & & & & & $-5.39^{\mathrm{a}}$ & - \\
\hline CCSD Tllmit & & & & & & & & & $-5.45^{\mathrm{a}}$ & - \\
\hline
\end{tabular}

${ }^{\mathrm{a}}$ Reference 45.

${ }^{b}$ aug-cc-pVTZ optimized geometry. 
plied to the energy obtained by subtracting the relaxed methanol energies. The convergence limit has also been validated by comparison to the experimentally derived binding energy. ${ }^{46}$ With this in mind, we can estimate that the value obtained by the aug-cc-pVDZ basis set has a small underestimation of $5 \%$ and considering the relative computational costs presented in Table II, the aug-cc-pVDZ basis set was chosen for the determination of the dimer interaction energy at the MP2 CP corrected level.

Since CP correction applied to fully optimized dimers including monomer relaxation is not well defined, we performed the following algorithm for the estimation of CP correction at the aug-cc-pVDZ basis set level. The dimer interaction was computed by subtracting the energies of the resulting methanol monomers in the fully optimized dimer from the energy of the dimer. The energies of these monomers were computed in the complete basis of the dimer. Then the deformation energy of each of these monomers with respect to the optimal one was computed in the same basis set and subtracted from the previous energy; using a much larger basis set as the aug-cc-pVQZ did not produce any significant difference in the deformation energy values. This algorithm allows for a better search of the optimal structure that does not necessarily correspond to the minimum of the energy surface computed ab initio, due to $\mathrm{CP}$ correction. Of course it is possible that $\mathrm{CP}$ overcorrects the interaction energy, but since CP is in itself small, this effect is negligible.

The monomer deformation energy $\$$ the dimer interaction energy $\mathrm{V}$, and the three-body nonadditivity calculated using the many-body expansion described in Ref. 47.

The three-body nonadditivities were computed with the $\mathrm{SCF}$ CP faug-cc-pVDZ level. The reason why correlation energy was not considered in these calculations is that it has been shown that correlation energy is quite additive $e^{3,48}$ and restriction to the uncorrelated level entails significantly less computer time. The same level of calculation was used to compute some four-body nonadditive terms in order to assess the magnitude of these contributions. They were found to be small enough - and reasonably well reproduced by the potential - to not merit the effort of adjusting to the whole four-body potential energy surface.

The sample points in the potential energy surfaces were chosen in an iterative manner. Thus, initial samples were taken from a regular scan of the hypersurface with respect to the different degrees of freedom. An initial potential parametrization was fitted to the preliminary samples and employed to predict, via numerical simulations at standard temperature, more monomers, dimers, and trimers in the gas phase as well as clusters appearing in the liquid phase. These structures were then computed at the ab initio level and added to the potential energy surface. This procedure continued until self-consistency was attained with the same accuracy as that obtained in the previous fitting. In this way, for instance, the optimal monomer energy predicted by the potential differs in only $0.06 \mathrm{kcal} / \mathrm{mol}$ with respect to that computed at the ab initio level. The final surfaces to be fitted consisted of 5 al $F_{\text {the }}$ polarizability and dipole moment of the optimal monomer, Bل555 monomer structures where both the deformation energy, relative to the optimal monomer, and the dipole were considered for fitting, tures where the interaction energy was fitted, and Aflin 53 trimer structures where the three-body nonadditive contributions where fitted.

The vibrational spectra presented in this work were calculated using the normal mode theory. ${ }^{49}$ In the condensed phase, the semiclassical method suggested by Reimers and Watts for water and ice ${ }^{50}$ was implemented. The spectra was calculated by averaging over 200 configurations taken from a Monte Carlo calculation with 500 molecules in the simulation cell. The configurations are separated by 100000 Monte Carlo steps.

\section{B. Model potential}

The model considered in this work uses a functional form based on the MCDHO model, ${ }^{4}$ as it allows for the inclusion of intramolecular flexibility, nonadditivity, and polarizability. The electron cloud of each atom of a molecule is represented as a negative mobile charge density with radial exponential decay, attached to a positively charged point by a harmonic oscillator to simulate the interaction between charges of atoms forming a chemical bond. All other chargecharge interactions consider all charges as points instead of densities.

The specific expression for the water-water interaction was given in Eqs. A general formulation, suitable to be used with larger molecules. In the following equations $r_{i j}=r_{i j}-r_{j}$ is the distance between the corresponding centers, either fixed positive nuclei $\mathrm{Z}$ or mobile negative charges $q$, where $i$ and $j$ subscripts correspond to sites $\mathrm{i}$ and $\mathrm{j}$.

The intramolecular energy is composed of the following terms.

[1]|⿴囗玉 The electrostatic interaction between atomic centers:

$$
\mathrm{U} \mathrm{Z}_{\mathrm{i}}, \mathrm{Z}_{\mathrm{j}} \text { 夙 } \frac{\mathrm{Z}_{\mathrm{i}} \mathrm{Z}_{\mathrm{j}}}{\mathrm{r}_{\mathrm{ij}}} \text {. }
$$

20150 The electrostatic interaction between mobile charge densities $q_{i}$ and the atomic center charge $Z_{j}$ of the bonded atoms, where ${ }_{1}$ is the intramolecular decay length of the chargedensity

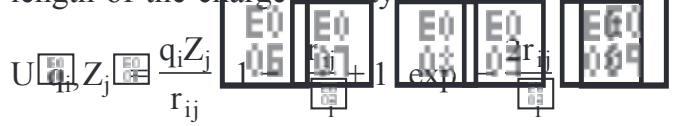

The mobile charge densities are considered as point charges when interacting with any other atomic center. In these cases the electrostatic interaction is given by

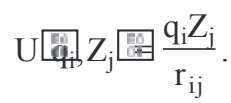

国卧 The interaction between mobile charges with decay lengths 5 and 5 attached to bonded atoms. In this case a two-center integral should be used; however, an approximate expression that gives good accuracy at all relevant distances was found, i.e., 
TABLE III. Parameters of the model potential. Distances are in a.u., angles in deg, and energy is in $\mathrm{kcal} / \mathrm{mol}$. The different parameters are described in the text. $\mathrm{R}_{\mathrm{c}}$ stands for the hard core cutoff radius used during simulation and are in a.u.

\begin{tabular}{|c|c|c|c|c|c|c|c|c|}
\hline Site & Site & Site & Site & Z & $\mathrm{q}$ & $\mathrm{k}$ & 圆 & \\
\hline $\mathrm{C}$ & & & & 3.900283 & -3.408234 & 569.650 & 1.223331 & \\
\hline $\mathrm{O}$ & & & & 0.366121 & -1.398671 & 435.404 & 1.597584 & \\
\hline $\mathrm{H}_{\mathrm{C}}$ & & & & 0.596934 & -0.601763 & 602.237 & 0.900642 & \\
\hline \multirow[t]{2}{*}{$\mathrm{H}_{\mathrm{O}}$} & & & & 1.990457 & -1.442636 & 455.769 & 0.849260 & \\
\hline & & & & $\mathrm{D}_{\mathrm{ij}}$ & $\square_{1 j}$ & $r_{i j}^{e q}$ & & \\
\hline $\mathrm{O}$ & $\mathrm{C}$ & & & 4.595276 & 0.977601 & 3.997212 & & \\
\hline $\mathrm{H}_{\mathrm{C}}$ & $\mathrm{C}$ & & & 70.427959 & 1.078138 & 2.292126 & & \\
\hline \multirow[t]{2}{*}{$\mathrm{O}$} & $\mathrm{H}_{\mathrm{O}}$ & & & 21.473454 & 1.584645 & 2.021717 & & \\
\hline & & & & $\mathrm{k}_{\square}$ & 4 & $\mathrm{k}_{\mathrm{UB}}$ & $r_{i k}^{0}$ & \\
\hline $\mathrm{H}_{\mathrm{C}}$ & $\mathrm{C}$ & $\mathrm{O}$ & & 89.700 & 109.471 & 7.957 & 3.955 & \\
\hline $\mathrm{C}$ & $\mathrm{O}$ & $\mathrm{H}_{\mathrm{O}}$ & & 42.007 & 107.800 & 26.103 & 3.782 & \\
\hline \multirow[t]{2}{*}{$\mathrm{H}_{\mathrm{C}}$} & $\mathrm{C}$ & $\mathrm{H}_{\mathrm{C}}$ & & 55.768 & 109.000 & 14.745 & 4.063 & \\
\hline & & & & $\mathrm{k}_{\square}$ & $\mathrm{n}$ & $\theta$ & & \\
\hline \multirow[t]{2}{*}{$\mathrm{H}_{\mathrm{C}}$} & $\mathrm{C}$ & $\mathrm{O}$ & $\mathrm{H}_{\mathrm{O}}$ & 0.118728 & 3 & 0.0 & & \\
\hline & & & & $\mathrm{A}_{\mathrm{ij}}$ & $a_{i j}$ & $\mathrm{~B}_{\mathrm{ij}}$ & $b_{i j}$ & $\mathrm{R}_{\mathrm{c}}$ \\
\hline $\mathrm{H}_{\mathrm{C}}$ & $\mathrm{H}_{\mathrm{O}}$ & & & 480.23197 & 0.17631 & -892.49599 & 0.04774 & \\
\hline $\mathrm{C}$ & $\mathrm{C}$ & & & 97519.61811 & 2.09463 & -2.29413 & 0.26626 & 5.6 \\
\hline $\mathrm{C}$ & $\mathrm{O}$ & & & 6496.79010 & 1.27607 & -1782.69982 & 0.95643 & 5.3 \\
\hline $\mathrm{C}$ & $\mathrm{H}_{\mathrm{C}}$ & & & 1644.35938 & 1.72179 & 10.90308 & 0.39432 & 4.2 \\
\hline $\mathrm{C}$ & $\mathrm{H}_{\mathrm{O}}$ & & & 435.95137 & 0.98575 & -2.76514 & 0.11954 & 3.7 \\
\hline $\mathrm{O}$ & $\mathrm{O}$ & & & 40041.92558 & 1.06555 & -36415.26163 & 1.04797 & 4.3 \\
\hline $\mathrm{O}$ & $\mathrm{H}_{\mathrm{C}}$ & & & 1634.41365 & 1.47724 & 0.13703 & 0.02435 & 3.7 \\
\hline $\mathrm{O}$ & $\mathrm{H}_{\mathrm{O}}$ & & & 4001.50520 & 2.03411 & 8.15927 & 0.29931 & 2.8 \\
\hline $\mathrm{H}_{\mathrm{C}}$ & $\mathrm{H}_{\mathrm{C}}$ & & & 2904.62284 & 2.09689 & -9.00616 & 0.47864 & 2.83 \\
\hline $\mathrm{H}_{\mathrm{C}}$ & $\mathrm{H}_{\mathrm{O}}$ & & & 1114.57406 & 1.20124 & -1132.26023 & 1.17835 & 2.83 \\
\hline $\mathrm{H}_{\mathrm{O}}$ & $\mathrm{H}_{\mathrm{O}}$ & & & 623.49048 & 1.19327 & -347.75515 & 0.96590 & 2.95 \\
\hline
\end{tabular}

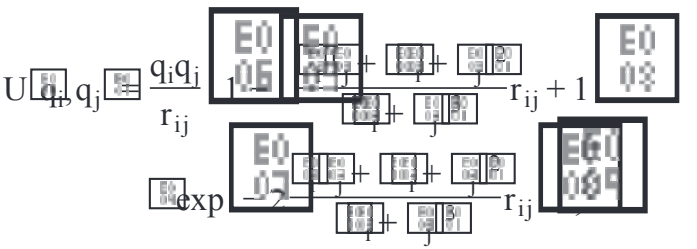

again the mobile charge densities are considered as point charges when interacting with mobile charge densities of nonbonded atoms

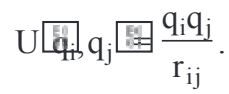

Alf with depth $\mathrm{D}_{\mathrm{ij}}$, inverse decay length rium parameter $r_{i j}^{e q}$,

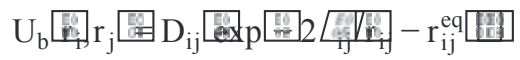

$$
\begin{aligned}
& -\exp 5 \frac{E_{i j}}{n_{i j}}-r_{i j}^{e q}
\end{aligned}
$$

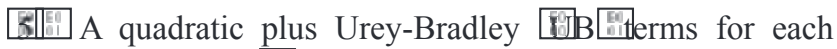
bond angle ${ }_{1}$, with parameters $\mathrm{k}_{\text {Gand }} \mathrm{k}_{\mathrm{UB}}$, and the equilibrium values $\frac{9}{\mathrm{Tjk}}$ and $\mathrm{r}_{\mathrm{ik}}^{0}$,

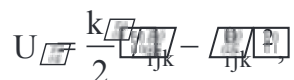

$$
\mathrm{U}_{\mathrm{UB}}=\frac{\mathrm{k}_{\mathrm{UB}}}{2} \mathrm{r}_{\mathrm{ik}}-\mathrm{r}_{\mathrm{ik}}^{0}[
$$

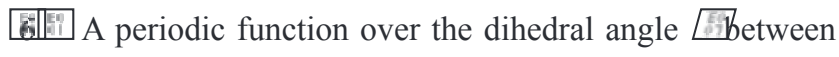
four consecutive bonded centers

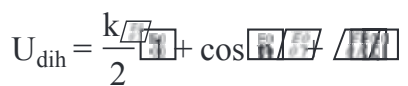

7. that do not form angles or covalent bonds.

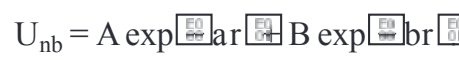

Hence the analytical expression to compute the intramolecular energy is

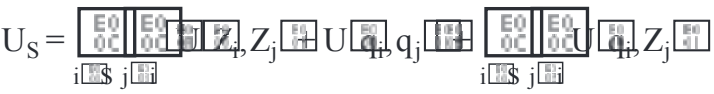

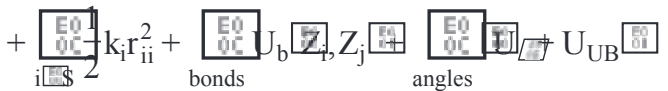

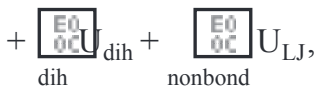

where the third term corresponds to the harmonic energy of the mobile charge at a distance $r_{i i}$ from its nucleus and the summation i ${ }^{\mathrm{B} S}$ refers to the entire molecule. 

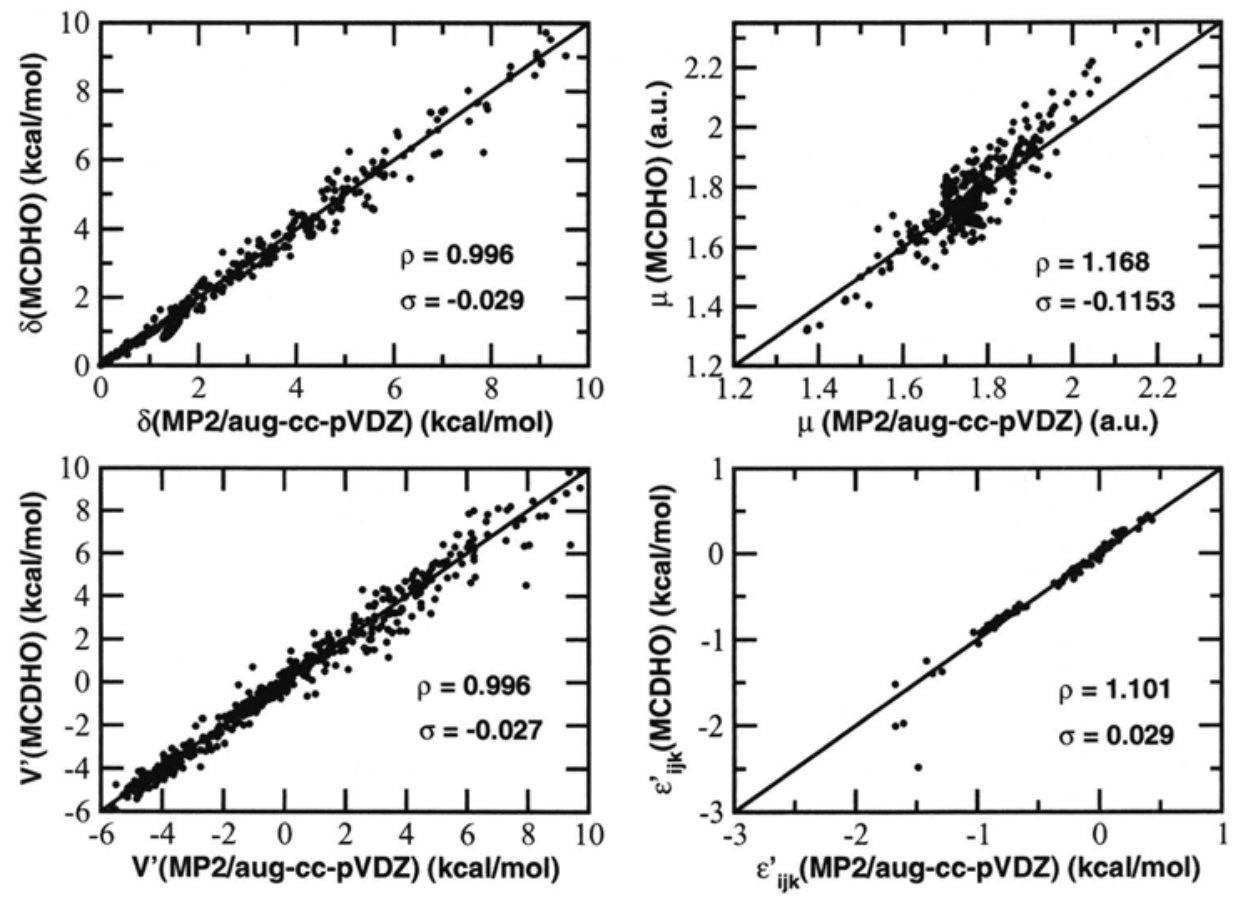

FIG. 1. Comparison between the monomer deformation energies $7 \mathbb{D}$ monomer dipole moments Whitimer interaction energies as described in Ref. 47 M.j. Ind three-body nonadditivities as described also in Ref. 47 HNlpedicted at the ab initio level and those predicted by the model for the same structures. terms.

The intermolecular energy is composed of the following

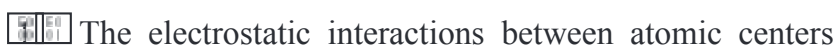
plus exponential terms with parameters $A_{i j}, B_{i j}, a_{i j}$, and $\mathrm{b}_{\mathrm{ij}}$;

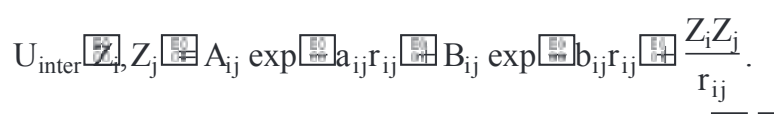

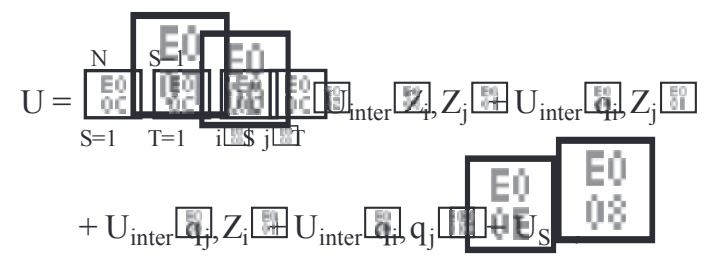

where summations $\mathrm{i}$ WS and $\mathrm{j}$ 監 refer to entire molecules. The interaction energy requires the subtraction of the in国卧 tramolecular energies of the isolated molecules, $\mathrm{U}_{\mathrm{S}}^{0}$,

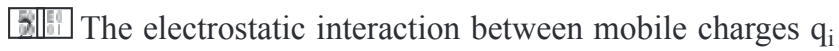
considered as point charges and charges $Z_{j}$,

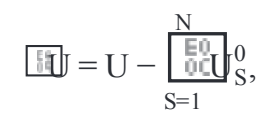

$$
\mathrm{U}_{\text {inter }} q_{\mathrm{i}}, \mathrm{Z}_{\mathrm{j}} \text { 成 } \frac{\mathrm{q}_{\mathrm{i}} \mathrm{Z}_{\mathrm{j}}}{\mathrm{r}_{\mathrm{ij}}} \text {. }
$$

3 The electrostatic interaction between mobile charges,

$$
\mathrm{U}_{\text {inter }} \text { 凮, } \mathrm{q}_{\mathrm{j}} \text { 畾 } \frac{\mathrm{q}_{\mathrm{i}} \mathrm{q}_{\mathrm{j}}}{\mathrm{r}_{\mathrm{ij}}} \text {. }
$$

Therefore, the energy of a cluster with $\mathrm{N}$ molecules is given by thus taking into consideration the energetic cost of polarizing and deforming each molecule in the cluster or the condensed phase.

Unlike the case of water, ${ }^{4}$ and because of the complexity of the potential energy surface due to the increased number of degrees of freedom, it was found convenient to use hard core cutoff radii for the interactions as part of the potential. So in addition to the set of parameters fitted to reproduce the surfaces, using the program VA05AD, ${ }^{51}$ the potential definition

TABLE IV. Structural parameters for the optimal methanol monomer. Comparison of MCDHO results against ab initio and experimental results. Error bars

\begin{tabular}{|c|c|c|c|c|c|}
\hline Method & $\mathrm{r} \mathrm{Co}$ & $\mathrm{r}$ & 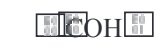 & $\mathrm{d}$ Н & $\square$ \\
\hline aug-cc-pVDZ & 1.4342 & 0.9659 & 107.9 & 180.00 & 1.71 \\
\hline MCDHO $0 \mathrm{~K}$ & 1.4386 & 0.9639 & 107.8 & 180.00 & 1.72 \\
\hline MCDHO $\longdiv { 2 9 8 } \mathrm { k }$ & $1.4423 \pm 0.0014$ & $0.9667 \pm 0.0004$ & $108.4 \pm 0.3$ & - & $1.72 \pm 0.01$ \\
\hline Expt. $^{\mathrm{a}}$ & 1.434 & 0.937 & 105.93 & - & 1.69 \\
\hline Expt. $^{\text {b }}$ & $1.4246 \pm 0.0024$ & $0.9451 \pm 0.0034$ & $108.53 \pm 0.48$ & - & - \\
\hline
\end{tabular}

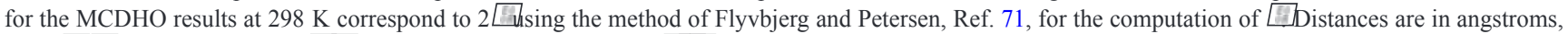

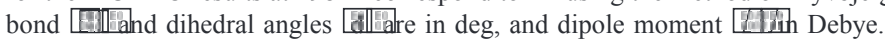

${ }^{\mathrm{a}}$ Reference 44

${ }^{\mathrm{b}}$ Reference 72 . 


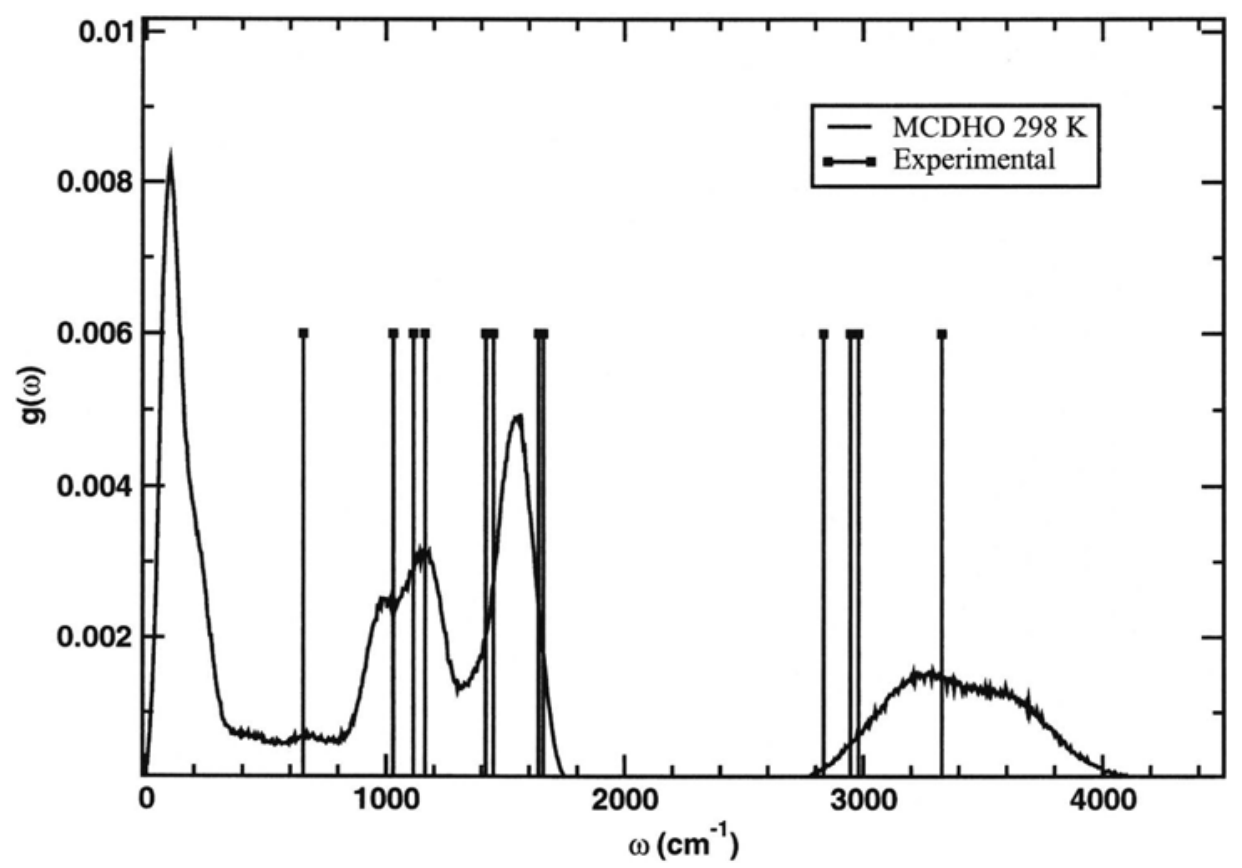

FIG. 2. Vibrational spectral density of liquid methanol, MCDHO, and experimental results.

includes a set of cutoff values. Differentiating the methyl hydrogen from the hydroxyl hydrogen also proved convenient, so they were treated as different atomic species.

\section{RESULTS}

\section{A. Model potential performance \\ 1. Reproduction of the adjusted properties}

The fitted parameters for the methanol-methanol potential and the corresponding cutoff values are presented in Table III. The quality of the reproduction of the monomer deformation energy surface and dipole moment is presented in Fig. 1, as well as the two-body interactions and the threebody nonadditivity. In addition the trace of the polarizability tensor also fitted by the model comes to be $\bar{E}=21.2, \&$ $=23.3$, and $E_{z 2}=18.8$ a.u. which compares rather well to the ab initio values $G_{A}=20.5, W_{y}=23.2$, and $W_{Z}=19.8$ a.u. and the experimental isotropic values of 21.8 Ref. 52 罝and 22.0 a.u. $^{53}$

\section{Reproduction of molecular clusters}

A comparison between the geometries of the optimal methanol monomer predicted by the model, the corresponding ab initio monomer, and the experimental values is presented in Table IV. A very good agreement of the model with the optimal ab initio structure was found. Furthermore, the Monte Carlo simulation of the single monomer at $298 \mathrm{~K}$ predicts geometrical values which are very close to the experimental ones.

In Fig. 2 the vibrational spectra of the methanol molecule in the liquid phase is presented and compared to the experimental data. It was computed via a normal mode analysis. In order to estimate the reliability of this treatment we compared its predictions for the water molecule with those estimated from the velocity autocorrelation in a molecular dynamics $\mathrm{MD}$ 巸imulation with the MCDHO potential by Stern et al. ${ }^{54}$ We can see in Table V that the two methods yield similar results for the shift from the gas to liquid phase, giving confidence in the application of the normal mode analysis to the methanol molecule. In Table VI the vibrational spectra predicted for the methanol molecule in

TABLE V. Vibrational frequencies of water in gas and liquid phases. All frequencies are in $\mathrm{cm}^{-1}$.

\begin{tabular}{|c|c|c|c|c|c|c|c|c|c|}
\hline & \multicolumn{2}{|c|}{ Expt. } & \multicolumn{2}{|c|}{$\begin{array}{r}\mathrm{MCDHO} \\
\mathrm{MD} \$\end{array}$} & \multicolumn{2}{|c|}{$\begin{array}{r}\text { MCDHO } \\
\text { NM }\end{array}$} & \multirow{2}{*}{$\begin{array}{c}\text { Expt. } \\
\text { Liquid-gas }\end{array}$} & \multirow{2}{*}{$\begin{array}{r}\mathrm{MCDHO} \\
\text { Liquid-gas }\end{array}$} & \multirow{2}{*}{$\begin{array}{r}\text { MCDHO } \\
\text { Liquid-gas }\end{array}$} \\
\hline & $\mathrm{Gas}^{\mathrm{c}}$ & Liquid $^{d}$ & Gas & Liquid & Gas & Liquid & & & \\
\hline $\mathrm{OH}$ symm. stretch & 3756 & 3557 & 3918 & 3668 & 3928 & 3742 & -150 & -250 & -186 \\
\hline $\mathrm{OH}$ antisymm. stretch & 3657 & & 3785 & 3407 & 3789 & 3346 & & -378 & -443 \\
\hline $\mathrm{HOH}$ bend & 1595 & 1670 & 1651 & 1740 & 1660 & 1754 & 75 & 89 & 94 \\
\hline
\end{tabular}

${ }^{\mathrm{a}}$ Reference 54.

${ }^{\mathrm{b}}$ Normal modes. This work.

${ }^{\mathrm{c}}$ Reference 73 .

${ }^{\mathrm{d}}$ Reference 74 . 
TABLE VI. Vibrational frequencies of methanol in gas and liquid phases. All frequencies are in $\mathrm{cm}^{-1}$.

\begin{tabular}{|c|c|c|c|c|c|c|c|}
\hline & \multirow{2}{*}{$\begin{array}{c}\text { aug-cc-pVDZ } \\
\text { Gas }\end{array}$} & \multicolumn{2}{|c|}{ Expt. $^{\mathrm{a}}$} & \multicolumn{2}{|c|}{ MCDHO } & \multirow{2}{*}{$\begin{array}{c}\text { Expt. } \\
\text { Liquid-gas }\end{array}$} & \multirow{2}{*}{$\begin{array}{l}\text { MCDHO } \\
\text { Liquid-gas }\end{array}$} \\
\hline & & Gas & Liquid & Gas & Liquid & & \\
\hline O-H stretch & 3839 & 3681 & 3328 & 3752 & 3679 & -353 & -73 \\
\hline \multirow[t]{2}{*}{ d-stretch } & 3189 & 3000 & 2980 & 3540 & 3478 & -20 & -62 \\
\hline & 3130 & 2960 & 2946 & 3260 & 3276 & -14 & 16 \\
\hline $\mathrm{CH}_{3}$ s-stretch & 3052 & 2844 & 2834 & 3252 & 3101 & -10 & -151 \\
\hline \multirow[t]{2}{*}{$\mathrm{CH}_{3}$ d-deform } & 1505 & 1477 & 1480 & 1592 & 1617 & 3 & 25 \\
\hline & 1494 & 1477 & 1480 & 1538 & 1617 & 3 & 79 \\
\hline $\mathrm{CH}_{3}$ s-deform & 1466 & 1445 & 1450 & 1521 & 1557 & 5 & 36 \\
\hline $\mathrm{O}-\mathrm{H}$ bend & 1367 & 1345 & 1418 & 1240 & 1492 & 73 & 252 \\
\hline \multirow{2}{*}{$\mathrm{CH}_{3}$ d-rock } & 1170 & 1165 & 1163 & 1167 & 1185 & -2 & 18 \\
\hline & 1076 & 1065 & 1115 & 1116 & 1093 & 50 & -23 \\
\hline $\mathrm{C}-\mathrm{O}$ stretch & 1046 & 1033 & 1030 & 981 & 973 & -3 & -8 \\
\hline Torsion & 315 & $200-295$ & 655 & 307 & 658 & $455-360$ & 351 \\
\hline
\end{tabular}

the gas and liquid phases are compared against the ab initio and experimental values. It can be seen that there is a reasonable agreement in the gas phase description, but less so for the liquid phase. In particular, the shift from gas to liquid phase for the $\mathrm{OH}$ bond stretch mode is much reduced.

The optimal methanol dimer predicted by the model is in very good agreement with the optimal ab initio dimer, as shown in Table VII. In Fig. 3 inset superposition of $a b$ initio and model optimum dimers is presented showing a discrepancy in a rotation along the hydrogen bond axis, something very difficult to prevent, e.g., it also occurred in the water dimer. ${ }^{4}$ A search for an ab initio CP corrected dimer as described previously produced the parameters presented in the third column of Table VII, which show a better agreement to the experimental values. There is also an improved agreement between the model optimal dimer and the CP corrected dimer.

Of course it is important to reproduce the hydrogen bond interaction not only in the single optimal structure. In Fig. 3 the interaction energy profile for the optimal approach of the methanol monomers along the hydrogen bond is presented showing an excellent agreement between the model and the ab initio curve.

In Table VIII and Fig. 4 we compare the optimal methanol trimers predicted by the model and the ab initio calculations. In this case it was not possible to find the CP corrected optimal structure since the ab initio optimization follows the $\mathrm{CP}$ uncorrected surface. But the optimal trimer predicted by the model when calculated at the ab initio level with $C P$ correction turned out to have a mere $0.14 \mathrm{kcal} / \mathrm{mol}$ difference with the one obtained by the ab initio minimization. Hence trimer structure reproduction is in good agreement with the ab initio calculation except for a small overestimation of the interaction energy and an overestimation of 国 $05 \AA$ in the oxygen-oxygen distance.

It is also important to look into the hexamer ring, since there is a discussion regarding the importance of this structure in the liquid phase of methanol, as well as a report ${ }^{31}$ on the possibility that simple potentials do not reproduce well this structure. In Table VIII we compare some structural parameters predicted by the model and ab initio calculations at the MP2 $/ 6-31++\mathrm{G}^{* *}$ level for the optimal hexamer. The table shows a general agreement between both structures. There is an apparent elongation of the hydrogen bond distance in the model predicted structure, but this elongation of $0.04 \AA$ is quite similar to the apparent elongation between the CP corrected and uncorrected structures at the ab initio level. Furthermore, the level of ab initio calculation is smaller than the one used for computing the energy surface, because of the computational cost involved, hence the agreement is quite adequate. From this it can be concluded that the model potential is reproducing the methanol clusters accurately and that it can be used to study the condensed phase.

\section{B. Numerical simulations}

The results obtained in reproducing the molecular properties, the interaction energies, and structures of small clusters support the reliability of the model potential in studies of the condensed phase. Liquid methanol simulations were carried out with the Monte Carlo Metropolis algorithm in the canonical ensemble $\mathbb{N}$ T 1 with periodic boundary conditions and Ewald summation. A cubic box of length $2.3437 \AA$ with 500 molecules was used to reproduce a standard density of $0.782 \mathrm{~g} / \mathrm{cm}^{3}$ at $298.15 \mathrm{~K}$. The procedure of updating only the polarization of the trial molecule colled single update has been criticized for lacking the condition of detailed balance ${ }^{55,56}$ that is sufficient but not necessary for a valid sampling; ${ }^{57}$ however, apart from hindering the convergence of the dipole-dipole correlation function, ${ }^{58}$ from which the dielectric constant can be computed, the single update scheme does not produce any significant error compared to algorithms that comply with detailed balance, ${ }^{55,56,59,60}$ but substantially increase the computational cost. Thus single update has been used in this work. 100 贯 $10^{6}$ configurations were used to attain equilibrium starting from a randomly generated configuration, and $100 \square 0106$ configurations were used for extracting the average values. We checked that both intramolecular and intermolecular degrees of freedom were equilibrated. For this we considered separately each energy

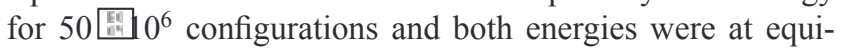
librium. 
TABLE VII. Structural parameters for the minimum energy methanol dimer. Comparison of MCDHO results against ab initio results. The third column corresponds to the counterpoise corrected dimer found as described

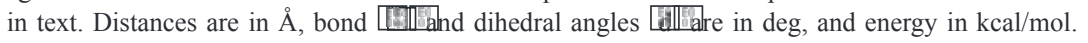

\begin{tabular}{|c|c|c|c|c|}
\hline & $\mathrm{MCDHO}$ & MP2/aug-cc-pVDZ & $\begin{array}{c}\text { MP2/aug-cc-pVDZ } \\
\text { Counterpoise corrected }\end{array}$ & Expt. \\
\hline $\mathrm{r}$ & 1.940 & 1.887 & 1.967 & \multirow{2}{*}{$\begin{array}{l}1.96 \pm 0.02^{\mathrm{a}} \\
-\end{array}$} \\
\hline $\mathrm{r} 0 \mathrm{O} \cdot \mathrm{O}$ & 2.892 & 2.847 & 2.920 & \\
\hline 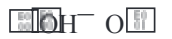 & 166.0 & 168.2 & 166.2 & - \\
\hline 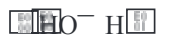 & 101.5 & 112.7 & 112.4 & - \\
\hline$\mathrm { d } \longdiv { \mathrm { COH } } \cdots \mathrm { O }$ & 159.8 & 132.3 & 131.3 & - \\
\hline$\mathrm { d } \longdiv { \mathrm { O } } \mathrm { H } \cdot \mathrm { OC }$ & -53.6 & -6.7 & -6.4 & - \\
\hline 國 & -5.27 & -5.11 & -5.15 & - \\
\hline
\end{tabular}

${ }^{\mathrm{a}}$ Reference 76.

The enthalpy of vaporization was computed as

$$
\mathrm{HH}_{\mathrm{vap}}=\mathrm{U}_{\mathrm{vap}}-\mathrm{U}_{\mathrm{liq}}+\mathrm{RT} \text {, }
$$

where $U_{\text {vap }}$ is the energy of the vapor phase and was calculated from a Monte Carlo simulation with a single molecule at $298 \mathrm{~K}$ in the same cubic box used for the liquid and using 1 國 $10^{6}$ configurations for equilibration and 5 - $10^{6}$ configurations to average the energy of the system. The vaporization enthalpy predicted $\mathrm{ITH}_{\mathrm{vap}}=8.81 \pm 0.04 \mathrm{kcal} / \mathrm{mol}$, which compares rather well with the reported experimental value of ${ }^{\left[\mathrm{F}_{\mathrm{H}}\right.} \mathrm{vap}_{\mathrm{p}}=8.946 \pm 0.005 \mathrm{kcal} / \mathrm{mol}^{61-63}$

The predicted molecular properties of the methanol molecule in the liquid phase and their experimental counterparts are presented in Table IX. There is a general agreement between the predicted and the experimental values except for the dipole moment which appears to be underestimated.
However, there is an ample discussion in the literature suggesting that the experimental value of $2.85 \mathrm{D}$ is overestimated. Pieruccini and Saija ${ }^{64}$ considered that the dielectric constant of 33 indicates a dipole in the liquid of 2.39 D. The same value has been proposed by Wick and Dang ${ }^{65}$ in a classical simulation and Handgraff and Meijer ${ }^{66}$ in a Car and Parinello simulation. Similarly Weerasinghe and Smith. ${ }^{67}$ with an empirical model and Martín et al. ${ }^{38}$ in a quantum mechanics/molecular mechanic simulation propose a value of $1.4 \mathrm{D}$. In summary the value predicted by the model is quite good and therefore all properties of the molecule in the liquid are well reproduced.

The total radial distribution function predicted by the model was estimated and compared with those of Yamaguchi et al. ${ }^{25}$ and Adya et al. ${ }^{26}$ in Fig. 5. The first two curves were constructed from the partial radial distribution functions using the weighting scheme suggested by Adya et al. ${ }^{26}$ In Fig. 5 the comparison shows that the disagreement between the

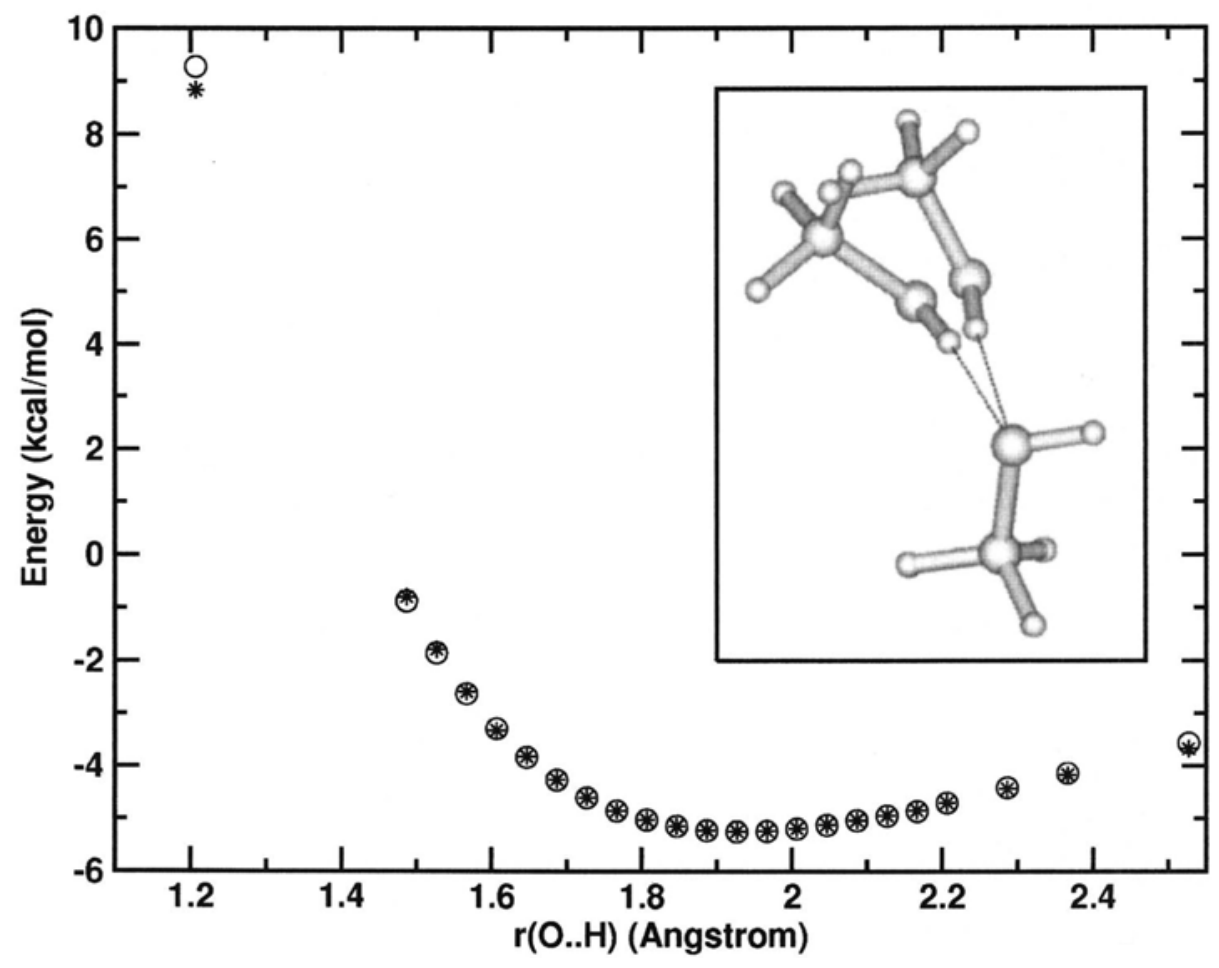

FIG. 3. Methanol-methanol dimer interaction energy along the hydrogen bond approaching line. MCDHO predicted values stars 6 vs ab initio results circles Inset: optimal methanol dimer predicted by the model top right $\square$ and the ab initio top left $\square$ ne. The geometries were superimposed on the oxygen atom and as close as possible to the oxydryl hydrogen and the carbon atom of the bottom monomer. 
TABLE VIII. Structural parameters for the optimal methanol trimer. Comparison between MCDHO and ab initio results at the MP2/aug-cc-pVDZ counterpoise corrected level Tieft columns 國nd geometrical parameters for the methanol hexamers might columns for the acceptor and donor oxygen in the hydrogen bonds. Distances are in $\AA$, bond $\square$ minhd dihedral angles $\square$ are in deg, and energies in $\mathrm{kcal} / \mathrm{mol}$. The model values correspond to the average and standard deviation values produced by slightly different geometries observed in the hexamer.

\begin{tabular}{|c|c|c|c|c|c|c|c|}
\hline & \multicolumn{2}{|c|}{ Trimer } & \multicolumn{3}{|c|}{ Ring hexamer } & \multicolumn{2}{|c|}{ Chain hexamer } \\
\hline & MCDHO & $\mathrm{Ab}$ initio & & MCDHO & $\mathrm{Ab}$ initio & MCDHO & $\mathrm{Ab}$ initio \\
\hline $\mathrm{r} \theta \cdot \mathrm{H}$ & 1.909 & 1.853 & 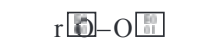 & $2.72 \pm 0.01$ & 2.68 & & \\
\hline $\mathrm{r} \theta \cdot \mathrm{H}$ & 1.959 & 1.881 & 四10-O-O & $109.5 \pm 4.1$ & 117.5 & & \\
\hline $\mathrm{r}$ & 1.889 & 1.860 & 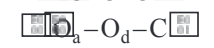 & $108.2 \pm 1.7$ & 106.3 & & \\
\hline $\mathrm{r}$. o & 2.819 & 2.766 & $\square \mathrm{Db}_{\mathrm{d}}-\mathrm{O}_{\mathrm{a}}-\mathrm{C}$ & $113.5 \pm 3.6$ & 119.4 & & \\
\hline $\mathrm{r}$ & 2.853 & 2.790 & $\mathrm{~d}[\mathrm{O}-\mathrm{O}-\mathrm{O}-\mathrm{O}$ & $59.7 \pm 6.5$ & 30.7 & & \\
\hline $\mathrm{r}$ & 2.800 & 2.766 & $\mathrm{~d}[\mathrm{O}-\mathrm{O}-\mathrm{O}-\mathrm{C}[\mathrm{D}$ & $167.7 \pm 6.2$ & 123.1 & & \\
\hline 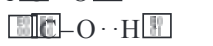 & 120.90 & 127.303 & & & & & \\
\hline 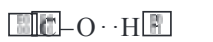 & 113.14 & 109.864 & & & & & \\
\hline 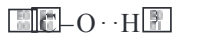 & 113.29 & 109.864 & & & & & \\
\hline $\mathrm{d}$ & -6.51 & -14.022 & & & & & \\
\hline $\mathrm{d}$ & -4.48 & -7.972 & & & & & \\
\hline $\mathrm{d}$ & 2.81 & -7.888 & & & & & \\
\hline 娄 & -16.18 & -15.22 & & -42.89 & -43.77 & -28.15 & -29.58 \\
\hline
\end{tabular}

theoretical and the experimental lines is similar to that shown between both experimental curves. This supports the validity of the potential; even if the theoretical peak is still slightly shifted towards longer distances.

We can go further and look into the radial distribution functions for different atomic pairs and compare to the experimentally derived curves of Yamaguchi et al. ${ }^{25}$ Figs. 6 and 7 FThere is a general agreement of the model radial distribution functions to those obtained from the experiment, except for the oxygen-oxygen radial distribution function, the one involved in the hydrogen bonding between methanol molecules, where the model presents a first peak at a distance about $0.1 \AA$ longer compared with the curves presented by Yamaguchi et al., ${ }^{25}$ and $0.08 \AA$ longer compared to the curve derived from the data presented by Adya et al. ${ }^{26}$ There is also a marked difference in the first minimum and the second peak, the experimental curve being more structured. These discrepancies are rather surprising considering the good agreement with all previous comparisons, either with ab initio or experimental counterparts. The possibility that the potential was not properly reproducing the nonadditivity in long hydrogen bonded structures, as suggested by Kashtanov et al., ${ }^{31}$ was considered, but it was shown that hexamers were properly reproduced. We also considered the fact that nonadditivity at the MP2 level was not computed because it is known that correlation energy is highly additive, ${ }^{48}$ but the possibility remains that, in these cases, these corrections were not negligible. Xantheas ${ }^{68}$ reported a substantial effect of MP2 corrections on water nonadditivity, but in that work a comparison is made between the optimal structures of the trimer predicted at the MP2 and those predicted at the self-

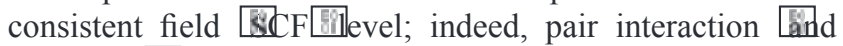
thus MP2 is crucial for structure determination, leading to different structures with different nanoadditivity values. Nonetheless in order to check if this could be a source of error, we computed the three-body nonadditivity surface at the MP2 level and compared it with the corresponding SCF surface. No meaningful difference appeared at any point. We also considered the possibility that the cell size was not large enough and it was hindering the formation of larger clusters. However, the radial distribution functions obtained with a cell containing 1000 molecules rendered the same results as those from the cell containing 500 molecules. It is clear that discrepancies between theoretical and experimental radial distribution functions are related to the hydrogen bonding. In a recent work it has been shown that both the radial distribution functions and the dipole moment are quite sensitive to pressure. ${ }^{65}$ Hence the observed differences could be due to a diminished pressure in the NVT simulation at the fixed experimental density. In order to check this a NPT simulation of the same system was performed at $1 \mathrm{~atm}$. The results show that the density obtained increases $0.03 \mathrm{~g} / \mathrm{cm}^{3}$ with respect to the previous experimental value of $0.782 \mathrm{~g} / \mathrm{cm}^{3}$, and the vaporization enthalpy becomes $\mathrm{Ft}_{\mathrm{vap}}$ $=8.99 \mathrm{kcal} / \mathrm{mol}$, getting closer to the experimental value. But the radial distribution functions did not change in any appreciable manner.

The only remaining explanation would be that since the level of ab initio calculations is slightly underestimating the binding energy, this would conduce to less compact structures. We have to recall that a small shift for the $\mathrm{OH}$ bond stretch mode was predicted between the gas and liquid phases, a deficiency that could be involved in the discrepancy observed. However, it is surprising that the vaporization energy is well reproduced being a very sensitive parameter. It could also be that the experimental biatomic radial distribution functions are reflecting some model dependency since the empirical potential structure refinement approach was used. $^{25}$

The model oxygen-oxygen radial distribution function indicates well defined first neighbors, but less defined second neighbors when compared to the equivalent water radial dis- 

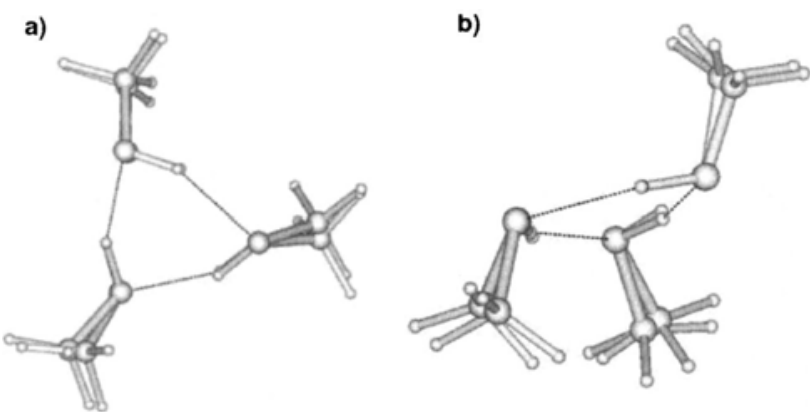

FIG. 4. Superposition of the trimer structures predicted ab initio and by the MCDHO model. Top alliand lateral hlliviews. Trimer superposition was done requesting superposition of the oxygen atoms by the molden program Ref. $78 \square$

tribution function, see, for example, Ref. 4. This suggests direct hydrogen bonding between the methanol molecules but not a tridimensional network as in the case of water. This agrees with the oxygen-hydroxyl hydrogen radial distribution function; the second peak is much smaller than its water counterpart. As a matter of fact, the solvation number of the first shell for the oxygen-oxygen radial distribution function is 2.1 which compares rather well with the experimental value of $1.77 \pm 0.07,{ }^{25}$ a value smaller than the 5.5 corresponding to water. Hence contrary to water, liquid methanol does not seem to make a three-dimensional 30 Findwork, but rather linear polymers.

With the results of the simulation it is possible to look into the existence of chains or rings of hydrogen bonded methanol molecules. Here, methanol linked molecules have been defined as such when alternated donor-acceptor hydrogen bonds were formed between them. Bifurcated hydrogen bonds were not considered for defining linkage, so that chains that could be joined by a bifurcated hydrogen bond were considered as independent polymers. In Fig. 8 one hexameric ring and one linear polymer found in the simulation box are shown. In Fig. 9 a histogram of the relative frequency of appearance of the different polymers, either chains or rings is presented. This histogram was constructed by av- eraging 100 snapshots taken each 100000 configurations and refers to the average number of clusters that occur in the simulation cell scaled by the number of molecules. A considerable amount of linear polymerization can be appreciated since fairly long chains appear. Even if the relative appearance of rings versus chains is small $44 \%$ The number of rings is important, taking into account that only 500 molecules were used in the simulation. Formation of rings could be frustrated by the size of the simulation cell. In order to check this, a simulation using 1000 molecules that increase the cell size slightly was performed. In this case the histogram corresponding to the linear chains is unaffected, whereas the one corresponding to rings has a different profile. The most common ring changes from 4 to 5 molecules. It could be that a larger cell size will predict a more frequent occurrence of rings with $n=6$ or larger, in agreement with Wilson et al. ${ }^{69}$ However, long chains, like the one presented in Fig. 8, give rise to faux rings, i.e., compact closed structure which are not really closed by hydrogen bonds and therefore they could be misleading the experimental interpretation.

It could be thought that the good performance of the potential is due to the inclusion of polarizability and intramolecular relaxation. As a matter of fact, there are several simulations including polarizability that have reproduced well the experimental data. ${ }^{35-38,66}$ Furthermore, in two of these works ${ }^{35,38}$ there was a comparison between the results produced by the potentials with and without polarization, indicating the need of polarization, even if some overstructuring could be occurring. ${ }^{36,38}$ In the present model it is possible to turn off some molecular properties while keeping the same force field parameters, henceforth making the elucidation of the need of such property independent of a change in potential. Keeping the mobile charges fixed at certain positions would freeze a particular charge distribution, hence, for instance, its dipole, and then a nonpolarizable potential can be used. Similarly, fixing the intramolecular internuclear distances will lead to a rigid potential. Since in both cases the particular structures are just restricting the adjusted hypersur-

TABLE IX. Average properties of the liquid methanol predicted by different forms of the model potential as described in the text and compared to experiment. Distances are in $\AA$, bond angles Finare in deg, dipole moment $1 \mathrm{H}$ in D, and energies in $\mathrm{kcal} / \mathrm{mol}$. Error bars for the MCDHO results at $298 \mathrm{~K}$ were calculated as $2 \square$ using the method of Flyvbjerg and Petersen, Ref. 71.

\begin{tabular}{|c|c|c|c|c|c|}
\hline Method & $\mathrm{r}$ & $\mathrm{rOH}$ & ElloH & $\square$ & Fi \\
\hline Expt. & $\begin{array}{c}1.415 \pm 0.003^{\mathrm{a}} \\
1.4246^{\mathrm{a}} \\
1.43 \pm 0.05^{\mathrm{d}} \\
1.42 \pm 0.04^{\mathrm{e}}\end{array}$ & $\begin{array}{c}0.961 \pm 0.001^{\mathrm{a}} \\
0.9451^{\mathrm{a}} \\
0.99 \pm 0.01^{\mathrm{d}} \\
1.027 \pm 0.008^{\mathrm{e}}\end{array}$ & $\begin{array}{c}111.0 \pm 3^{\mathrm{a}} \\
108.54^{\mathrm{a}} \\
112 \pm 3^{\mathrm{d}} \\
103.4 \pm 1.2^{\mathrm{e}}\end{array}$ & $2.85^{\mathrm{b}}$ & $-8.946 \pm 0.005^{\mathrm{c}}$ \\
\hline Fully flexible & $1.4457 \pm 0.001$ & $0.9751 \pm 0.0001$ & $107.22 \pm 0.04$ & $2.385 \pm 0.002$ & $-8.81 \pm 0.04$ \\
\hline Rigid pol. ggas. prop. & & & & $2.281 \pm 0.008$ & $-8.78 \pm 0.04$ \\
\hline Rigid nonpol. gas. prop. & & & & 1.71 & $-6.73 \pm 0.07$ \\
\hline Rigid pol. Tid. prop & & & & $2.309 \pm 0.002$ & $-8.68 \pm 0.006$ \\
\hline Rigid nonpol. Iid. prop. & & & & 2.309 & $-8.44 \pm 0.05$ \\
\hline
\end{tabular}

${ }^{\mathrm{a}}$ Reference 26

${ }^{\mathrm{b}}$ Reference 77.

${ }^{\mathrm{c}}$ References 61-63.

${ }^{\mathrm{d}}$ Reference 28.

${ }^{\mathrm{e}}$ Reference 27. 


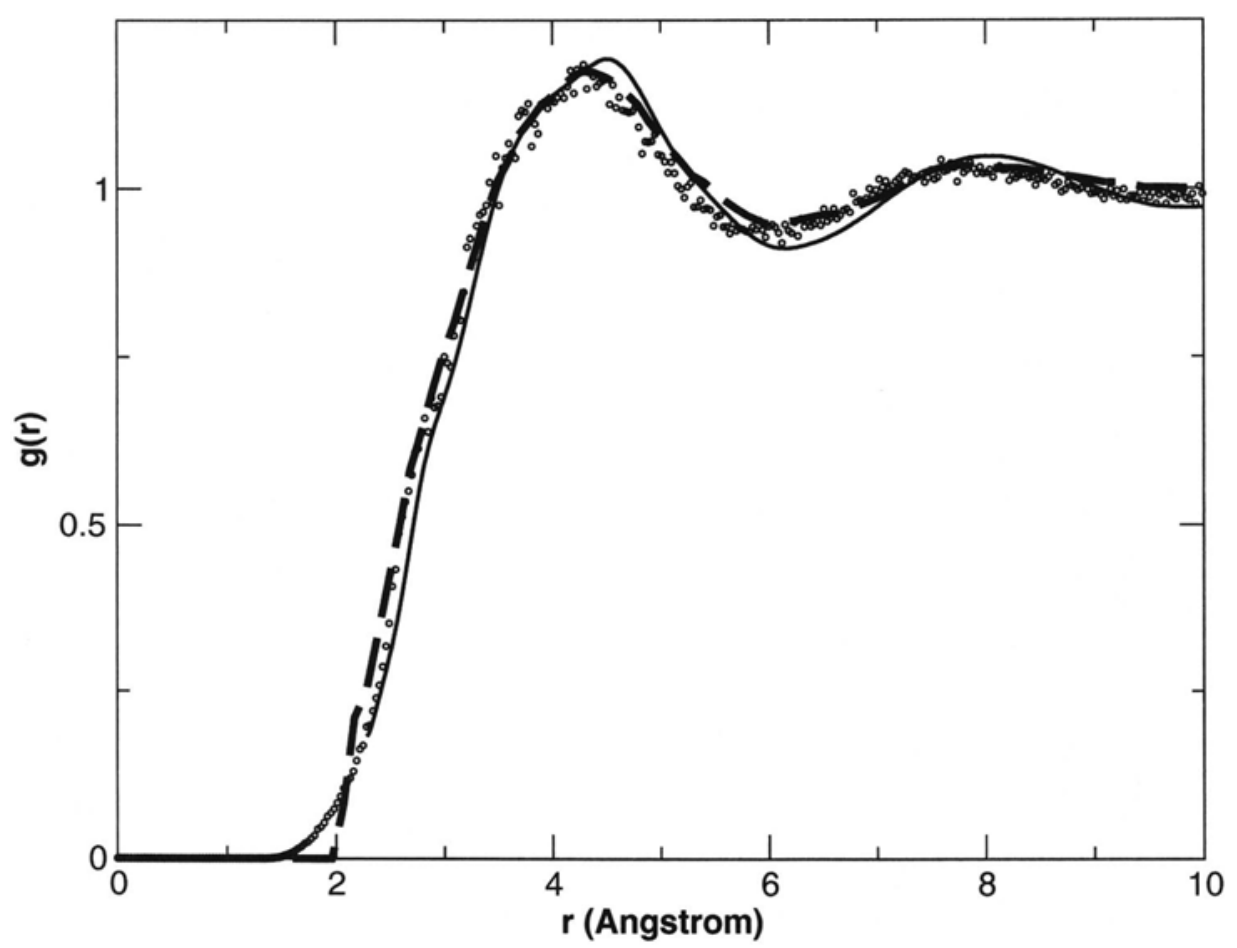

FIG. 5. Methanol weighted sum of radial distribution functions for $\mathrm{X}-\mathrm{X}$ atoms. Experimental data from Adya et al. Ref. 26 THashed line Tilexperimental data from Yamaguchi et al. Ref. 25 illoircles, and the MCDHO predicted curve Eontinuous line Dit Weights were taken from Adya et al. Ref. 26-

face, there is no need for any change in the force field parameters. This idea was used to analyze the effect of the molecular properties in the performance of a water potential $^{58}$ and also to propose the construction of effective potentials through the use of effective molecular properties rather than the use of an effective force field. Here the same idea is tested for the methanol potential.

In Table IX the vaporization enthalpies and the dipole moments predicted by the fully flexible potential, and several other model potentials are presented: a rigid polarizable potential and a rigid nonpolarizable potential using the gas phase properties as well as a rigid polarizable potential and a rigid nonpolarizable potential using the liquid methanol properties. The rigid polarizable models with either the gas or the liquid methanol geometry produces a vaporization enthalpy slightly smaller but still close to the experimental value. The dipolar moment predicted by these models is smaller than that of the fully flexible due to the rigid con-
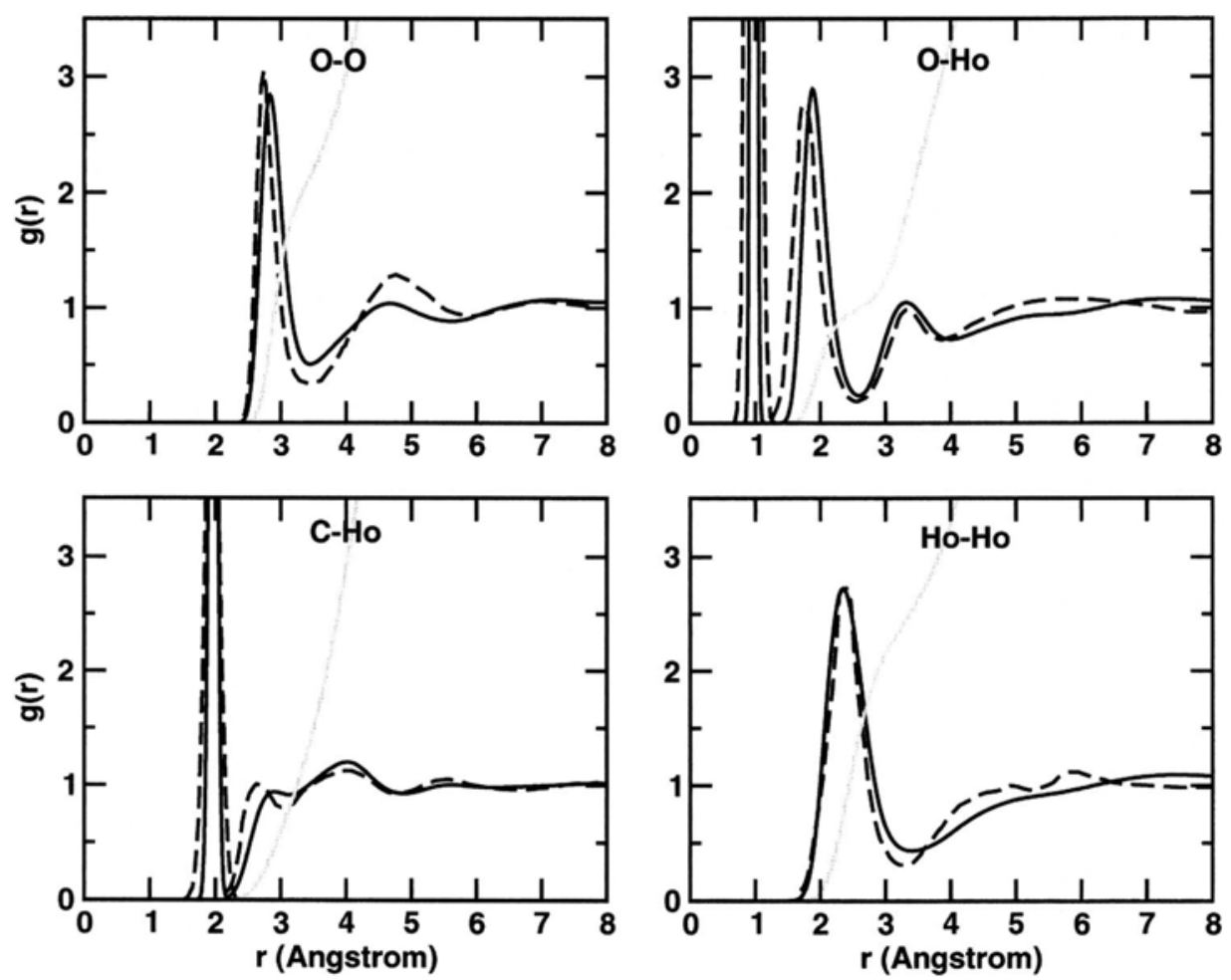

FIG. 6. Radial distribution functions for liquid methanol and solvation number gay line $\$$ MCDHO predicted curves eontinuous lines dompared to the experimental curves Gashed lines Hof Yamaguchi et al. Ref. 25 

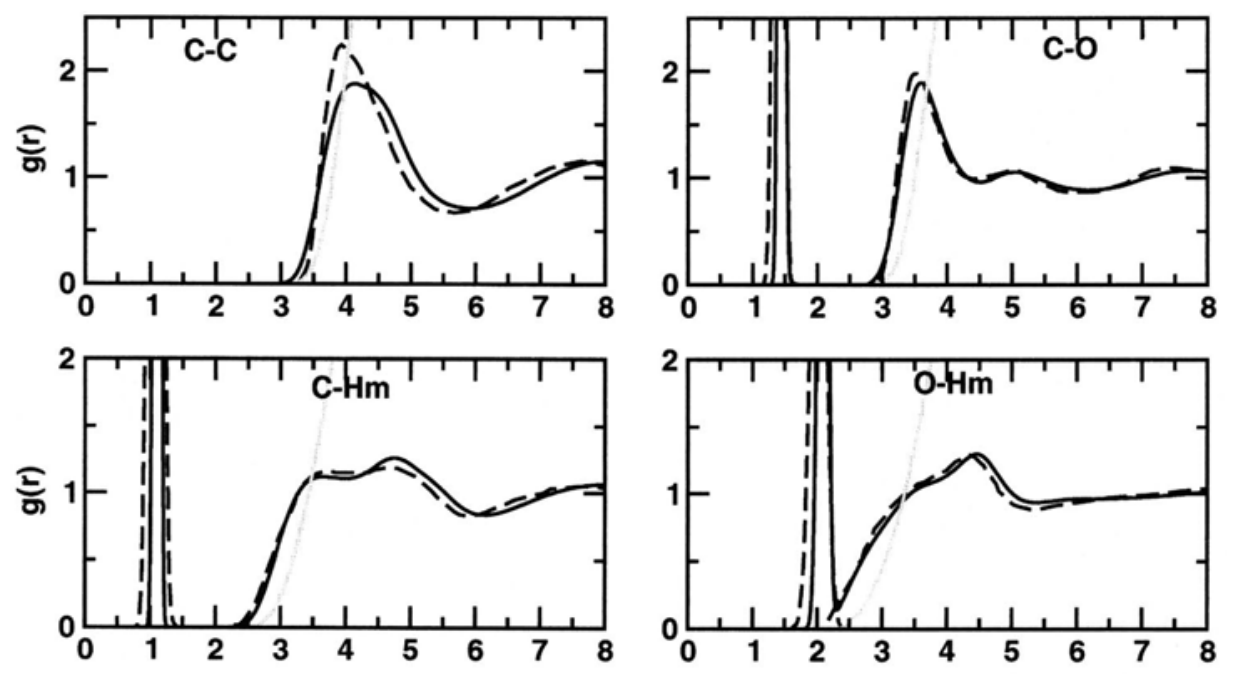

FIG. 7. Radial distribution functions for liquid methanol and solvation number guay line $\mathrm{ECDHO}$ predicted curves Eontinuous lines pared to the experimental curves Gashed lines Hof Yamaguchi et al. Ref. 25
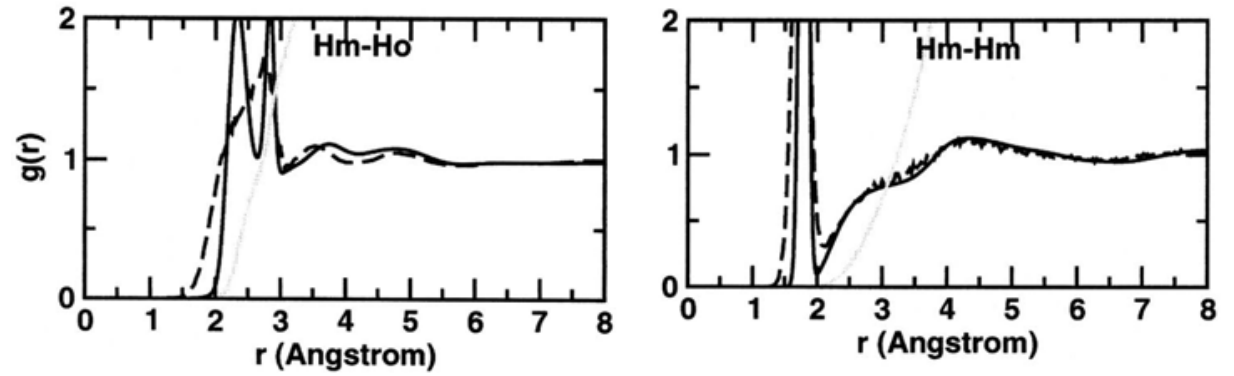

figuration of the molecule. Obviously, the similar performance is due to the very small change in geometry from gas to liquid phase. The rigid nonpolarizable model with gas phase dipole moment produces a vaporization enthalpy much reduced. If the liquid average dipole is used instead of the gas phase one, the rigid polarizable model still yields a value close to the fully flexible potential. It is interesting that intramolecular flexibility of methanol is not critical.

In Fig. 10 the oxygen-oxygen radial distribution functions predicted by the above models are presented. The rigid polarizable models yield distribution functions almost indistinguishable between them and very similar to the fully flexible, whereas the rigid nonpolarizable model with the gas

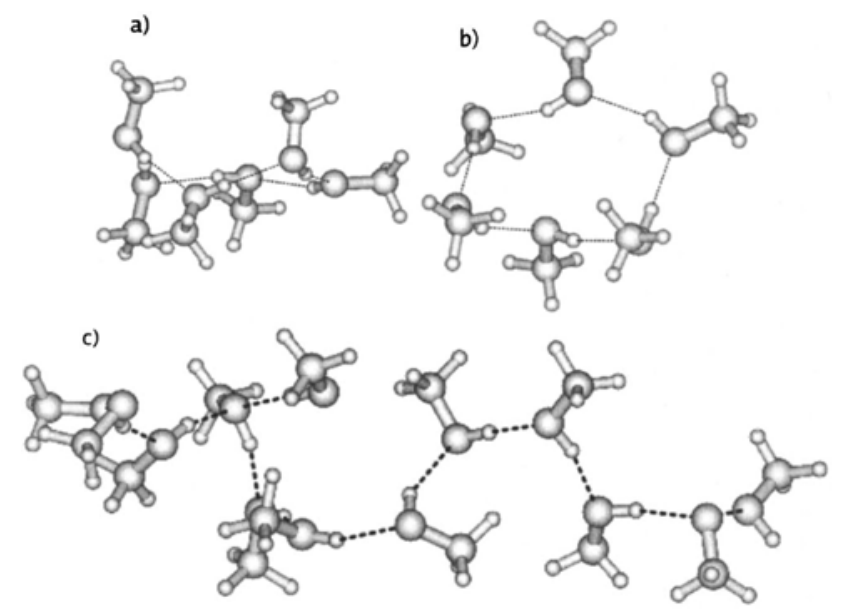

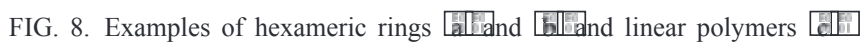
extracted from the liquid methanol simulation box.
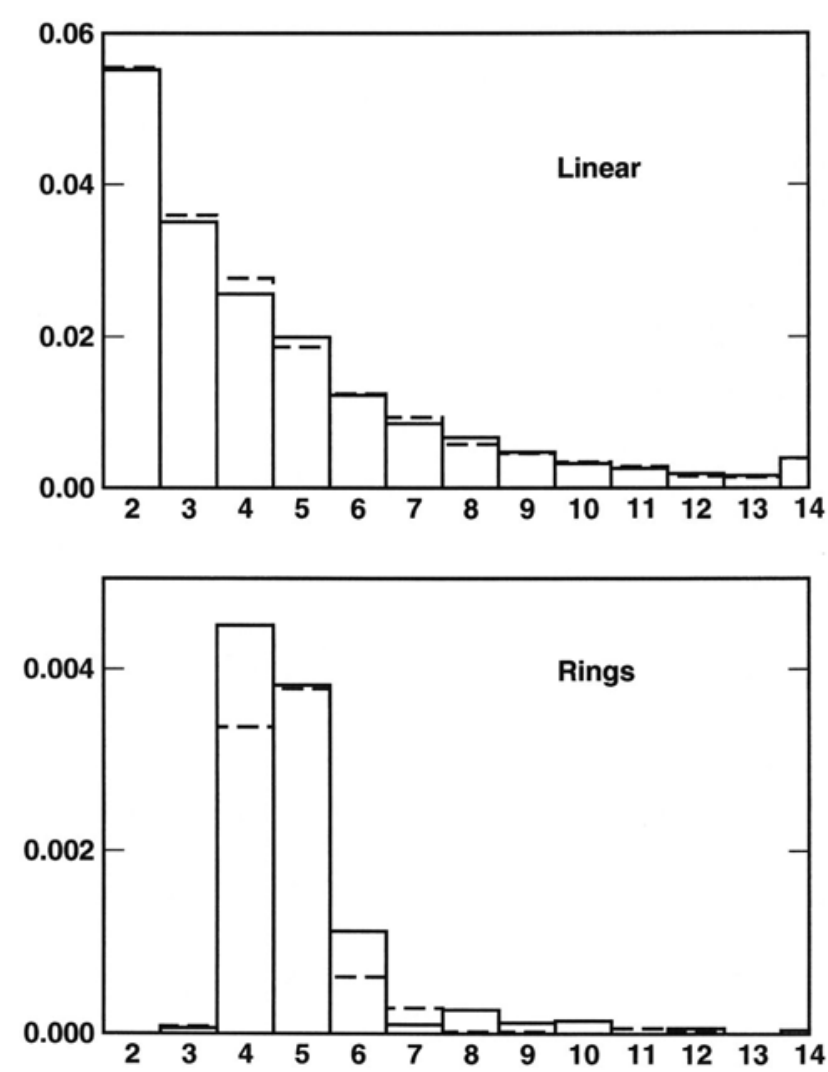

FIG. 9. Average number of linear ⿷hains pearing in 100 snapshots that occurred each 100000 configurations, scaled by the number of molecules. Continuous line from simulation with 500 molecules. Broken line from simulation with 1000 molecules. 


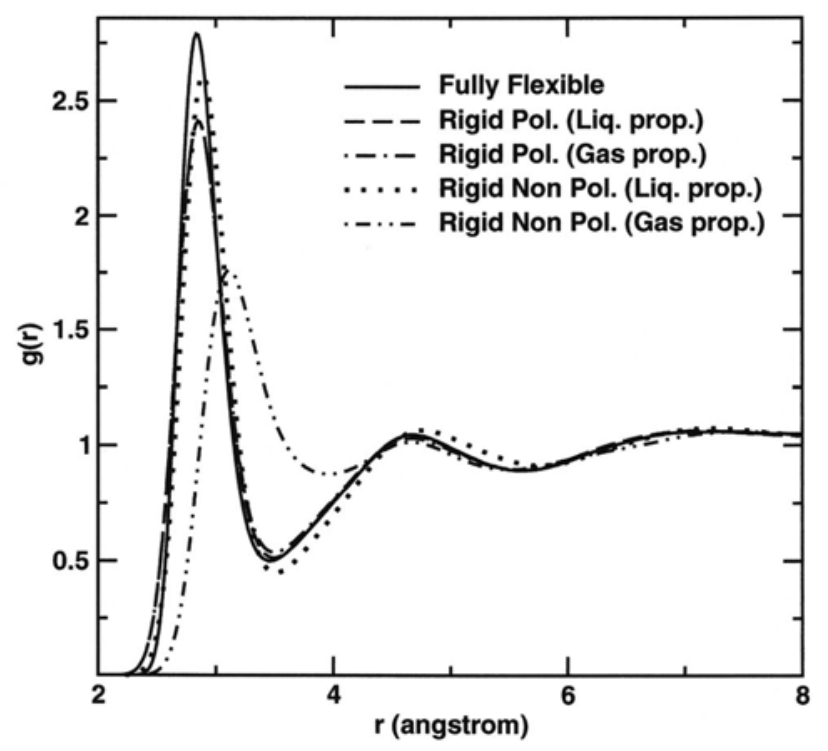

FIG. 10. Radial distribution functions predicted with the MCDHO models with different degrees of freedom.

phase dipole yields a function poorly structured. When the liquid properties are used for the rigid nonpolarizable model the structure function is greatly improved and it is now very similar to that obtained with the fully flexible model. Hence for the proper reproduction of liquid methanol a polarizable model is required either by including polarizability in the potential or modifying the molecular property to include the liquid value of the dipole in the case of methanol and dipole and geometry in the case of water. ${ }^{58}$ Effective pair potentials can be constructed to yield reasonable, or even good reproductions of the liquid phase ${ }^{67}$ but they certainly will not reproduce the interaction of small clusters or respond to thermodynamic conditions different from those used to construct the effective potentials. ${ }^{13}$

\section{CONCLUSIONS}

A methanol-methanol potential derived from ab initio calculations has been presented. This potential has been proven to reproduce the molecular properties as well as the structure and interaction energies of small clusters. The liquid methanol properties are well reproduced, except for small discrepancies in the radial distribution functions.

It is also clear that there is an absolute need for a polarizable model, or an effective model that has taken polarizability into account, for the proper description of the system.

There is a good agreement between the structural and energetic values of the model clusters and the ab initio prediction, but the model has a tendency to yield slightly less compact structures and slightly less favorable energy, in clusters and in the liquid phase.

An analysis of the different types of clusters that appear in the liquid phase shows that both chains and rings appear, chains are able to grow to considerable size, and rings can grow up to heptamers, even if less frequently. This agrees with the NMR Eef. 70 Eand x-ray absorption ${ }^{69}$ observations and explains how the highly structured network of methanol molecules is responsible for the peculiar properties of the substance without resulting in a waterlike 3D network.

\section{ACKNOWLEDGMENTS}

This work was supported by CONACyT Grant No. V50479-R 罗and DGAPA-UNAM Grant No. IN111706 are grateful to Reyes Garcia Carreon for his help in the computational part of this work.

${ }^{1}$ H. Saint-Martin, C. Medina-Llanos, and I. Ortega-Blake, J. Chem. Phys. 93, 6448 1990

${ }^{2}$ J. M. Martínez, J. Hernández-Cobos, H. Saint-Martin, R. R. Pappalardo, I. Ortega-Blake, and E. Sánchez-Marcos, J. Chem. Phys. 112, 2339 500 E

${ }^{3}$ M. Carrillo-Tripp, H. Saint-Martin, and I. Ortega-Blake, J. Chem. Phys. 118,7062 [2003

${ }^{4}$ H. Saint-Martin, J. Hernández-Cobos, M. I. Bernal-Uruchurtu, I. OrtegaBlake, and H. J. C. Berendsen, J. Chem. Phys. 113, 10899000

${ }^{5}$ P. Y. Ren and J. W. Ponder, J. Phys. Chem. B 107, 5933 203

${ }^{6}$ R. Ayala, J. Martínez, R. Pappalardo, H. Saint-Martin, I. Ortega-Blake, and E. Sánchez-Marcos, J. Chem. Phys. 117, 10512 ए02

${ }^{7}$ R. Ayala, J. Martinez, R. Pappalardo, and E. Sanchez-Marcos, J. Chem. Phys. 119, 9538 [2003 Di

${ }^{8}$ M. W. Mahoney and W. L. Jorgensen, J. Chem. Phys. 112, 8910 Do0

${ }^{9}$ C. J. Burnham, J. C. Li, S. S. Xantheas, and M. Leslie, J. Chem. Phys. 110,4566 瞒99

${ }^{10}$ S. W. Rick, S. J. Stuart, and B. J. Berne, J. Chem. Phys. 101, 6141 W94 II

${ }^{11}$ J. Hernández-Cobos, I. Ortega-Blake, M. Bonilla-Marín, and M. MorenoBello, J. Chem. Phys. 99, 9122 1993

${ }^{12} \mathrm{~J}$. Hernández-Cobos and I. Ortega-Blake, J. Chem. Phys. 103, 9261 [995 [D

${ }^{13}$ J. Hernandez-Cobos, H. Saint-Martin, A. Mackie, L. Vega, and I. OrtegaBlake, J. Chem. Phys. 123, 044506 [205

${ }^{14}$ G. Olah, A. Goeppert, and G. Prakash, Beyond Oil and Gas: The Methanol Economy Wiley-VCH, Weinheim, 2006

${ }^{15}$ B. M. Ladanyi and M. S. Skaf, Annu. Rev. Phys. Chem. 44, $335 \square 993$

${ }^{16}$ B. H. Torrie and S. X. Weng, Mol. Phys. 67, 575 [9989

${ }^{17}$ K. J. Tauer and W. N. Lipscomb, Acta Crystallogr. 5, 606 囵52

${ }^{18}$ M. Haughney, M. Ferrario, and I. R. McDonald, J. Phys. Chem. 91, 4934 W87 ए5

${ }^{19}$ W. L. Jorgensen, J. Am. Chem. Soc. 103, 134 1981

${ }^{20}$ E. Tsuchida, Y. Kanada, and M. Tsukada, Chem. Phys. Lett. 311, 236 \$999

${ }^{21}$ J. W. Haandgraaf, T. S. van Erp, and E. J. Meijer, Chem. Phys. Lett. 367, 617 [2003

${ }^{22}$ J. A. Morrone and M. E. Tuckerman, J. Chem. Phys. 117, 4403 2002

${ }^{23}$ M. Pagliali, G. Cardini, R. Righini, and V. Chettino, J. Chem. Phys. 119, 66552003

${ }^{24}$ T. Yamaguchi, K. Hidaka, and A. K. Soper, Mol. Phys. 96, 1159 \$99

${ }^{25}$ T. Yamaguchi, K. Hidaka, and A. K. Soper, Mol. Phys. 97, 603 \$99

${ }^{26}$ A. K. Adya, L. Bianchi, and C. J. Wormald, J. Chem. Phys. 112, 4231 2000 目

${ }^{27}$ D. G. Montague, I. P. Gibson, and J. C. Dore, Mol. Phys. 44, 1355 1910

${ }^{28}$ Y. Tanaka, N. Ohtomo, and K. Arakawa, Bull. Chem. Soc. Jpn. 58, 644 W84 [I]

${ }^{29}$ A. H. Narten and A. Habenschuss, J. Chem. Phys. 80, 3387 1984

${ }^{30}$ M. Magini, G. Paschina, and G. Piccaluga, J. Chem. Phys. 77, 2051 \$82 Di

${ }^{31}$ S. Kashtanov, A. Augustson, J. Rubensson, J. Nordgren, H. Ågren, J. H. Guo, and Y. Luo, Phys. Rev. B 71, 104205 [205[

${ }^{32}$ T. Kosztolnyi, I. Bak, and G. Palinks, J. Chem. Phys. 118, 4546 [03

${ }^{33}$ J. Gao, D. Habibollazadeh, and L. Shao, J. Phys. Chem. 99, 16460 \$95

${ }^{34}$ L. Bianchi, A. K. Adya, O. N. Kalugin, and C. J. Wormald, J. Phys.: Condens. Matter 11, 9151 \$99 5

${ }^{35}$ A. Sum, S. Sandler, R. Bukowski, and K. Szalewicz, J. Chem. Phys. 116, 7627 2002

${ }^{36}$ H. Yu, D. Geerke, H. Liu, and W. van Gunsteren, J. Comput. Phys. 27, 1494 [206

${ }^{37}$ S. Patel and C. L. BrooksIII, J. Chem. Phys. 122, 024508 [2005 
${ }^{38}$ M. Martín, M. Sánchez, F. O. del Valle, and M. Aguilar, J. Chem. Phys. 116,1613 \$02 50

${ }^{39}$ M. J. Frisch, G. W. Trucks, H. B. Schlegel et al. Gaussian 98, Revision A.7, Gaussian, Inc., Pittsburgh, PA, 1998.

${ }^{40}$ D. E. Woon and T. H. Dunning, J. Chem. Phys. 98, 1358 1993 URL: http://link.aip.org/link/?JCP/98/1358/1

${ }^{41}$ R. A. Kendall, T. H. Dunning, and R. J. Harrison, J. Chem. Phys. 96, 6796 T992 Lee URL: http://link.aip.org/link/?JCP/96/6796/1

${ }^{42}$ T. H. Dunning, J. Chem. Phys. 90, 1007 1989 [9. See URL: http:// link.aip.org/link/?JCP/90/1007/1

${ }^{43}$ J. Wang, R. Boyd, and A. Laaksonen, J. Chem. Phys. 104, $7261 \$ 996$ Fi

${ }^{44}$ E. V. Ivash and D. M. Dennison, J. Chem. Phys. 21, $1804 \square 53 \square$

${ }^{45} \mathrm{~S}$. Tsuzuki, T. Uchimaru, K. Matsumura, M. Mikami, and K. Tanabe, J. Chem. Phys. 110, 11906 1999 [1\$ee URL: http://ink.aip.org./link/?JCP/ $110 / 11906 / 1$

${ }^{46}$ M. Kone, B. Illien, J. Graton, and C. Laurence, J. Phys. Chem. A 109, 11907 505

${ }^{47}$ N. Pastor and I. Ortega-Blake, J. Chem. Phys. 99, $7899 \square 993$

${ }^{48}$ V. F. Lotrich and K. Salewicz, J. Chem. Phys. 106, $9668 \square 997 \square$

${ }^{49}$ E. B. Wilson, J. C. Decius, and P. C. Cross, Molecular Vibrations Dbver, New York, 1980

${ }^{50}$ J. Reimers and R. Watts, Chem. Phys. 91, 201 1984

${ }^{51}$ M. J. F. Powell, Harwell Subroutine Library, 1969.

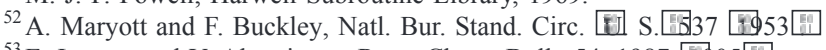

${ }^{53}$ E. Ivanov and V. Abrosimov, Russ. Chem. Bull. 54, 1987 D05 E.

${ }^{54}$ H. A. Stern, F. Rittner, B. J. Berne, and R. A. Friesner, J. Chem. Phys. 115,22375015

${ }^{55}$ M. G. Martin, B. Chen, and J. I. Siepmann, J. Chem. Phys. 108, 3383 1998

${ }^{56}$ M. P.edota, P. T. Cummings, and A. A. Chialvo, Mol. Phys. 99, 349 5010

${ }^{57}$ V. I. Manousiothakis and M. W. Deem, J. Chem. Phys. 110, $2753 \square 99$

${ }^{58}$ H. Saint-Martin, J. Hernández-Cobos, and I. Ortega-Blake, J. Chem.
Phys. 122, 224509 505

${ }^{59}$ B. Chen, J. J. Potoff, and J. I. Siepmann, J. Phys. Chem. B 104, 2378 2000 [i]

${ }^{60}$ M. Predota, P. T. Cummings, and A. A. Chialvo, Mol. Phys. 100, 2703 2002 [D

${ }^{61}$ J. Polak and G. Benson, J. Chem. Thermodyn. 3, 235 1971

${ }^{62}$ R. C. Wilhoit and B. J. Zwolinski, J. Phys. Chem. Ref. Data 2, 2 773

${ }^{63}$ B. P. Sahli, H. G. Gager, and A. J. Richard, J. Chem. Thermodyn. 8, 179 $\square 96$

${ }^{64}$ M. Pieruccini and F. Saija, J. Chem. Phys. 121, 3191 204

${ }^{65}$ C. D. Wick and L. X. Dang, J. Chem. Phys. 123, 184503 [2005 E.

${ }^{66}$ J.-W. Handgraaf and E. J. Meijer, J. Chem. Phys. 121, 10111 Q604

${ }^{67}$ S. Weerasinghe and P. E. Smith, J. Phys. Chem. 109, $15080 \square 05$

${ }^{68}$ S. Xantheas, J. Chem. Phys. 100, 7523 1994

${ }^{69}$ K. Wilson, M. Cavalleri, B. Rude, R. Schaller, T. Catalano, A. Nilsson,

R. Saykally, and L. Petterson, J. Phys. Chem. B 109, 10194 [2005

${ }^{70}$ J. Guo, Y. Luo, A. Augustsson, S. Kashtanov, J.-E. Rubensson, D. K. Shuh, H. Agren, and J. Nordgren, Phys. Rev. Lett. 91, 157401 [03 [6] See URL: http://link.aps.org/abstract/PRL/v91/e157401

${ }^{71}$ H. Flyvbjerg and H. G. Petersen, J. Chem. Phys. 91, 461 \$89

${ }^{72}$ R. M. Lees and J. G. Baker, J. Chem. Phys. 48, $5299 \square 68 \mathrm{~m}$

${ }^{73} \mathrm{G}$. Hertzberg, Electronic Spectra and Electronic Structure of Polyatomic Molecules Wan Nostrand Reinhold, New York, 1996

${ }^{74}$ S.-H. Chen, K. Toukan, C.-K. Loong, D. L. Price, and J. Teixeira, Phys. Rev. Lett. 53, 1360 1984

${ }^{75}$ T. Shimanouchi, Tables of Molecular Vibrational Frequencies 1 S. Department of Commerce, Washington, D.C., 1972 WVol. 1.

${ }^{76}$ F. J. Lovas and H. Hartwig, J. Mol. Spectrosc. 185, 98 1997 ED

${ }^{77}$ A. McClellan, Tables of Experimental Dipole Moments [Rhara Enterprises, El Cerrito, 1989

${ }^{78}$ G. Schaftenaar and J. Noordik, J. Comput.-Aided Mater. Des. 14, 123 Q00 